\title{
1. Consumer preferences for meat products blended with plant-based proteins in Germany
}

\author{
A. Profeta ${ }^{a}$, M.C. Baune ${ }^{a}$ \\ ${ }^{a}$ DIL e.V. - German Institute of Food technology, Prof.-von-Klitzing-Straße 7, 49610 D-Quakenbrück, Germany
}

\section{Abstract}

High levels of meat consumption are increasingly being criticised for ethical, environmental, and social reasons. Plant-based meat substitutes have been identified as healthy sources of protein in comparison to meat. This alternative offers several social, environmental and health benefits and may play a role in reducing meat consumption. However, there has been a lack of research on how specific meat substitute attributes can influence consumers to replace or partially replace meat in their diets.

Research demonstrates that in many countries consumers are highly attached to meat.They consider it as an essential and integral element of their daily diet. For these consumers which are not interested in vegan or vegetarian alternatives to meat, so-called meathybrids could be a lowthreshold option for a more sustainable food consumption behaviour. In meathybrids only a fraction of the meat product (e.g. 20\% to 50\%) is replaced with plant-based proteins.

In this paper, the results of an online survey with 500 German consumers are presented with focus on preferences and attitudes relating to meathyrids. The results show that more than fifty percent of consumers substitute meat at least occasionally. Thus, about half of the respondents reveal an eligible consumption behaviour in respect to sustainability and healthiness to a certain degree. Concerning the determinants of choosing either meathybrid or meat it becomes evident that the highest effect is exerted by the health perception. The healthier meathybrids are perceived, the higher is the choice probability. Thus, this egoistic motive seems to outperform altruistic motives like animal welfare or environmental concerns when it comes to choice for this new product category.

6 Keywords: meat substitute, meathybrid, consumer preference, plant proteins

\section{Introduction}

There are more than 7.7 billion people on this planet, with forecasts predicting the population to grow to 9.7 billion by 2050 (Max Roser and Ortiz-Ospina, 2013). Securing a sustainable food supply for humankind is therefore becoming a major challenge. Diets with a high share of animal proteins must be adapted in order to ensure that demand is not outstripping production (De Boer et al. 2014: Hallström et al. 2014). Furthermore, the consumption of meat and meat products ${ }_{13}$ in larger portions is associated with higher risks on prevalence of cardiovascular, coronary and 14 cerebrovascular diseases, stroke, diabetes type 2 and colorectal cancer (Richi et al., 2015).

15 In addition to these health issues, meat production chains have a considerable impact on the en16 vironment through the use of land, application of fertilisers, greenhouse emissions, and water 
consumption resulting in loss of biodiversity and enhancing climate change (Kroeze and Bouwman, 2011; De Vries et al., 2011; Erisman et al., 2011; Profeta and Hamm, 2019). Meat and meat products are also associated with severe animal welfare issues, such as pigtail docking, poultry debeaking, calves separation and the mistreatment in slaughterhouses (Grandin, 2018; Dawkins, 1980).

Diversity in eating habits is getting lost because developing countries adopt a more animal-rich, western style diet. In this context Sans and Combris (2015) stated that humankind is heading for a generalization of its diet through animal proteins.

These facts underline the importance of integrating new protein sources into the diet. However, this means overcoming barriers such as traditional meat consumption across many cultures (Stoll-Kleemann and Schmidt, 2017). To this effect, a promising alternative pathway is to increase the share of plant proteins in the diet. This could be done by using, e.g. textured soy protein, mushroom, wheat gluten, pulses etc. as a complete substitute for animal-protein. Another opportunity is to replace only a fraction of the meat product (e.g. $20 \%$ to $50 \%$ ) with plant-based proteins (Neville et al., 2017). Research demonstrates that in many countries consumers are highly attached to meat and consider it as essential and integral element of their daily diet (Graça et al. (2015). So-called meathybrids may be an option for the broad consumer segment that is not interested in vegan or vegetarian alternatives to meat. In meathybrids only a fraction of the meat product (e.g. $20 \%$ to $50 \%$ ) is replaced with plant-based proteins. Therefore, meathybrids could serve as a low-threshold offer for this group facilitating the transition in direction to a more healthy and sustainable diet.

As with many novel technologies, consumers' lack of understanding of hybrid meat products may led to scepticism and ultimately to the rejection of these. Through early integration of consumer demand and preferences into the development process, more suitable hybrid products can be designed. Understanding the decision-making process will help to develop tailored communication messages that highlight its benefits as a sustainable and healthy alternative to regular meat products.

The study aims on identifying consumer attitudes and preferences for meat alternatives such as meathybrids. Based on a literature overview, a representative online-survey was carried out in Germany.

\section{Consumer attitudes and preferences relating to meat and meat alternatives and meathy- brid characteristics}

The literature analysis focuses on the time period 2010-2020 for presenting the status quo of knowledge about consumer demand for meat and meat alternatives. Elderly articles entered the analysis only if these delivered a fundamental contribution to the research. The research databases and search engines - EBSCO host, Google Scholar, Research Gate and Science Direct were selected for literature research. The following search terms were chosen: meat consumption, food choice motives +meat, food choice $\&$ meat, meat alternatives, meat replacer, preferences \& meat consumption, attitudes \& consumption etc. Furthermore, in the found papers a cross-check was applied in order to identify additional papers.

\subsection{Sensory}

Concerning meat consumption, there is a consensus that consumer preferences are in particular affected by products' sensory characteristics. An inferior or low sensory quality can consti- 
tute a critical barrier for market entry of meat substitutes (Hartmann and Siegrist. 2017; Tucker 2014). Therefore, meat substitutes respectively meathybrids must catch up with real meat products concerning sensory characteristics. A study carried out by Topcu et al. (2015) demonstrated that the sensory quality factors aroma (29.6\%) and visible quality (5.3\%) explained most of Turkish consumers' preferences for red meat consumption compared to hedonic factors (e.g., product image, nutritional value, cost, meat source and durability, the origin of the meat).

Sensory appeal often is problematic in reducing or changing meat consumption to alternatives like in vitro (cultured, lab grown, etc.) meat, eating nose-to-tail (e.g., offal, hooves, eyes etc.) or entomophagy (eating insects) (Hartmann and Siegrist, 2017). The replacement of meat by plant proteins without altering sensory characteristics as well as technological properties is a major challenge. Application of plant proteins is limited as their composition and properties highly depend on the isolation method as well as environmental factors. For example, Akwetey et al. (2012) reported that only 5\% of ground beef could be replaced with whole cowpea flour in emulsion-type sausages without any negative effects on their sensory and physico-chemical properties. Zayas and Lin (1989) reported that the addition of $2 \%$ preswelled corn germ protein to frankfurters already changes the viscosity of the meat batter. Furthermore, an increase in off-flavour and off-aroma was observed with time in storage

\subsection{Environment}

Meat production causes more emissions per unit of energy compared with that of plant-based foods because energy is lost at each trophic level. It is the most important source of methane, which has a relatively high global warming potential, but a lower half-life in the environment compared with that of $\mathrm{CO}_{2}$ (Godfray et al. 2018). Carbon footprint of plant-based foods on average is twice as low as impact of pork (McAuliffe, 2015), while the impact in some other categories can be more than 60 times lower (Zhu and van Ierland 2004). Incorporation of plant biomass into pork products in equal proportion lead to the reduction of their environmental impact.

The majority of Western European consumers are not aware that meat consumption has a large environmental impact (Hartmann and Siegrist, 2017; Profeta, 2019; Macdiarmid et al., 2016). Contrarily, Apostolidis and McLeay (2016) stated that the ecological rationale for switching to meat alternatives is being recognised but cannot overcome sensory shortcomings (see above). Concerning consumer segments, Mullee et al.(2017) found that vegetarians are more likely than semi-vegetarians to agree that meat production is bad for the environment and unhealthy.

\subsection{Animal welfare}

A study among Belgian consumers explored the relationship between morality and diet choice by investigating how animal and human welfare attitudes can predict a meat eating vs. flexitarian vs. vegetarian diet (De Backer and Hudders, 2015). Results show that animal health concerns (measured via an animal attitude scale) can predict diet choice. Vegetarians are most concerned, while full-time meat eaters are least concerned. The contrast between flexitarians and vegetarians is greater than the contrast between flexitarians and full-time meat eaters (De Backer) and Hudders, 2015).

\subsection{Health}

It is known that frequent consumption of processed meat can increase the risk of cario vascular disease as well as all-cause mortality (Bernstein et al., 2010; Sinha et al., 2009). By contrast 
a higher intake of whole grains, legumes, and nuts is associated with cardiovascular benefits due to the intake of less saturated fatty acids and dietary cholesterol and more soluble fibers and poly unsaturated fatty acids ( $\mathrm{Hu}, 2003$, Chalvon-Demersay et al. 2017). However, plant proteins often have an incomplete amino acid profile because certain essential amino acids are not present in sufficient quantities, e.g. sulfuric amino acids in legumes or lysin in cereals. For this reason they must be mixed with other vegetable proteins or food that contain these amino acids in sufficient concentrations (Young and Pellett, 1994).

It is to highlight, that many consumers consider meat products as an important source of nutrients and a traditional component of their diet. It is generally perceived as a healthy food (Verbeke, 2015). Concerning gender, in the latter study women tended to be more interested in plant foods (meat is often associated with masculinity). A quarter of the respondents believed that eating vegetarian food frequently is unhealthy. More than half of semi-vegetarians did not agree that meat consumption is per se unhealthy. Like in the study of De Backer and Hudders (2015) omnivores associated meat with good health and disagreed that meat production is bad for the environment. Perceived healthiness has been a positive predictor of red meat consumption. Furthermore, among omnivores and flexitarians that represent a potential target group for meathybrids there are large consumer segments that consider meat substitutes as unhealthy and artificial. Thus in the communication strategy for meat substitutes the mentioned prejudice must be dealt with and re-framed.

\subsection{Meat attachment}

Recent research put forward the idea that consumers have an affective connection towards meat that may play a role in their willingness to change consumption habits (Graça et al., 2015). It is argued that the affection towards meat may represent a continuum in which one end refers to disgust (i.e., negative affect and repulsion, related with moral internalization), while the other shows a pattern of attachment (i.e., high positive affect and dependence towards meat, and feelings of sadness and deprivation when considering abstaining from meat consumption) that may hinder a change in consumption habits (Graça et al. 2015). Meat attachment mirrors the main characteristic of the general concept of attachment, which is the presence of a positive bond and desire to maintain closeness to the object of attachment.

In this study 15 out of the 16 items of the Meat Attachment Questionnaire of Graça et al. (2015) were selected for measuring the psychometric construct.

\subsection{Food Neophobia (FNS)}

Food neophobia refers to reluctance to eat unfamiliar foods (Pliner and Hobden, 1992). It has been the subject of a plethora of studies across many countries, and it affects the quality as well variety of foods in the diet (Capiola and Raudenbush, 2012; Damsbo-Svendsen et al. 2017, Falciglia et al., 2000, Henriques et al., 2009, Knaapila et al. 2007). The knowledge about population segments that have greater or lesser neophobia, allows to identify early adopters of innovative products (Vidigal et al., 2015).

According to Tucker (2014) more elderly consumers more likely hold negative views towards in vitro meat. They saw in vitro not as real meat, not as something natural, and hence unhealthy. It is to hypothesise that possibly this finding could hold for meathybrids that are partly highly processed as well. According to Apostolidis and McLeay (2016) low levels of acceptance for meat substitutes have been associated with high levels of the construct food neophobia.

In this study the food neophobia scale (FNS) of Pliner and Hobden (1992) was selected for measuring the psychometric construct. 


\section{Data collection and methods of data analysis}

Consumer data was collected using a quantitative online survey approach. The respondents have been recruited by the market research company Savanta (London, UK). The questionnaire comprised questions about the general meat consumption on the one hand and on the other hand specific questions concerning preferences for meat substitutes.

The online survey was carried out in Germany with 500 respondents. Participants had to be meat eaters and thus vegetarians and vegans were sorted out. Furthermore, the participants had to be mainly, respectively to 50\% responsible for food shopping in the household

The study design and the practicability of the questionnaire were tested in a pretest with 20 participants. The pretest results led to slight changes in the questionnaire design. Data collection took place in the time period from 8th November until 19th November 2019 (see Table 1).

In the result section, we report descriptive results. For scale development (FNS, MAQ) Cronbach's alpha is calculated and reported. For measuring FNS, the list of Pliner and Hobden(1992) was selected. The wording of the German version has been chosen from a study by Siegrist and Hartmann (2019). Participants answered on a five-point response scale that verbally and numerically anchored ( $1=$ totally disagree, $2=$ disagree, $3=$ =neither disagree nor agree, $4=$ agree, $5=$ totally agree). The five-point scale was used instead of the originally used seven-point scale for a better display of the questionnaire on tablets and smartphones. The items indicated with (r) in Table 4 were inversely re-coded. Considering that the inclusion of invalid items creates the risk of invalid conclusions (Hartmann et al., 2015), a principal components analysis (Varimax rotation, eigenvalues greater than one) and a confirmatory factor analysis were carried out to explain the variability of the FNS.

For MAQ, participants answered on a five-point response scale that was verbally and numerically anchored ( $1=$ strongly disagree, $2=$ disagree, $3=$ neither disagree nor agree, $4=$ agree, $5=$ strongly agree). The items indicated with (r) in Table 4 were inversely re-coded. Like for the FNS, a principal component analysis and a confirmatory factor analysis were carried out.

Furthermore, a multinomial logistic regression model is applied for measuring the impact of several parameters on the the choice of either a hybrid or a meat product.

\subsection{Logistic regression analysis}

Logistic regression is the regression analysis to conduct when the dependent variable is nominal with more than two levels. It is used to model nominal outcome variables, in which the $\log$ odds of the outcomes are modeled as a linear combination of the predictor variables. The multinomial logistic model belongs to the family of generalized linear models and as mentioned is used when the response variable is a categorical variable (Long and Freese, 2001).

Suppose that variable $Y_{i}$ represents the offered alternatives in a choice experiment (e.g. choice between meat and meathybrid), with $i=1, \ldots, n$ and $n$ is the number of possible product alternatives. In case $n$ equals 2 and $Y$ has outcomes $Y_{1}$ and $Y_{2}$. Both the counts of $Y_{1}$ and $Y_{2}$ follow a binomial distribution. The probability of occurrence of $Y_{1}$ is $\pi_{1}$ and that of $Y_{2}$ is $\pi_{2}$. Logistic regression relates probability $\pi_{1}$ to a set of predictors using the logit link function:

$$
\operatorname{logit}\left(\pi_{1}\right)=\ln \left(\frac{\pi_{1}}{\pi_{2}}\right)=\ln \left(\frac{\pi_{1}}{1-\pi_{1}}\right)=\mathbf{x}^{\prime} \beta
$$

where $\mathbf{x}$ is a vector of predictors (e.g. FNS, MAQ or buying frequency of organic meat), and $\beta$ is a vector of model coefficients that are typically estimated by maximum likelihood. Equation 1 
can be rewritten as:

$$
\left(\frac{\pi_{1}}{1-\pi_{1}}\right)=\exp \left(\mathbf{x}^{\prime} \beta\right)=\exp (\eta)
$$

The quotient in Equation 2 is referred to as the odds. From Equation 2 follows that:

$$
\pi_{1}=\frac{\exp (\eta)}{1+\exp (\eta)}
$$

The binomial logistic regression model is easily generalized to the multinomial case. If there are $n$ product alternatives there are also $n$ variables $Y_{1}, \ldots, Y_{n}$ with corresponding probabilities of occurrence $\pi_{1}, \ldots, \pi_{n}$. Analogous to binomial logistic regression the odds $\pi_{1} / \pi_{n}, \ldots, \pi_{n}-1 / \pi_{n}$ are modelled by means of $\exp \left(\eta_{1}\right), \ldots, \exp \left(\eta_{n-1}\right)$. From $\sum_{i=1}^{n} \pi_{i}=1$ it follows that:

$$
\pi_{1}=\frac{\exp \left(\eta_{i}\right)}{\exp \left(\eta_{1}\right)+\exp \left(\eta_{2}\right)+\ldots+\exp \left(\eta_{n}\right)}
$$

where $\exp \left(\eta_{n}\right)=0$. This model ensures that all probabilities are in the interval $[0,1]$ and that the probabilities sum to 1 .

In this paper the dependent variable is taken from a comparison task where respondents had to indicate if they would either choose meat, the meathybrid alternative or none of these options. The FNS and MAQ-scale as well as other parameters entered the regression analysis as independent variables. These independent variables are the buying frequency of organic/free range meat, the buying frequency of plant-based alternatives and the evaluation if either meathybrid or meat is perceived as healthier, better for the environment, more tasty or better for the environment. Given the theoretical background, data was modelled according to the following expression:

$$
\begin{aligned}
\mathbf{x}^{\prime} \beta= & \text { buy.freq. organic/free range } * \beta_{1} \\
& + \text { healthier } * \beta_{2} \\
& + \text { more tasty } * \beta_{3} \\
& + \text { better for the environment } * \beta_{4} \\
& + \text { better for animal welfare } * \beta_{5} \\
& + \text { FNS } * \beta_{6} \\
& + \text { MAQ } * \beta_{7} \\
& + \text { buy.freq. plant-based alternatives } * \beta_{8} \\
& + \text { constant }
\end{aligned}
$$

The above mentioned parameters are estimated for meathybrid $\left(Y_{1}\right)$ and the "none"-option $\left(Y_{2}\right)$ whereas meat $\left(Y_{3}\right)$ was set as reference category in the estimation. From the estimation results odds ratios are calculated. Odds ratios in logistic regression can be interpreted as the effect of a one unit of change in $\mathrm{X}$ in the predicted odds ratio with the other variables in the model held constant.

In this study for estimating the specified model the software R ( $\mathrm{R}$ Core Team, 2020) and the package mlogit (Croissant, 2020) were used. For visualisation of odds ratios from the estimated model the package sjplot (Lüdecke, 2020) was applied. 


\begin{tabular}{|c|c|c|c|}
\hline attribute & characteristics & $\mathbf{n}$ & $\%$ \\
\hline \multirow[t]{2}{*}{ gender } & male & 245 & 49.0 \\
\hline & female & 255 & 51.0 \\
\hline \multirow{16}{*}{$\begin{array}{l}\text { federal } \\
\text { state }\end{array}$} & Baden-Württemberg & 66 & 13.2 \\
\hline & Bavaria & 75 & 15.0 \\
\hline & Berlin & 22 & 4.4 \\
\hline & Brandenburg & 15 & 3.0 \\
\hline & Bremen & 5 & 1.0 \\
\hline & Hamburg & 10 & 2.0 \\
\hline & Hesse & 37 & 7.4 \\
\hline & Mecklenburg-Vorpommern & 10 & 2.0 \\
\hline & Lower Saxony & 50 & 10.0 \\
\hline & North Rhine-Westphalia & 114 & 22.8 \\
\hline & Rhineland-Palatinate & 20 & 4.0 \\
\hline & Saarland & 5 & 1.0 \\
\hline & Saxony & 26 & 5.2 \\
\hline & Saxony-Anhalt & 15 & 3.0 \\
\hline & Schleswig-Holstein & 15 & 3.0 \\
\hline & Thuringia & 15 & 3.0 \\
\hline \multirow[t]{6}{*}{ age } & $<25$ years & 65 & 13.0 \\
\hline & $25-34$ years & 66 & 13.2 \\
\hline & $35-44$ years & 99 & 19.8 \\
\hline & $45-54$ years & 84 & 16.8 \\
\hline & $55-64$ years & 73 & 14.6 \\
\hline & $>64$ years & 113 & 22.6 \\
\hline \multirow[t]{7}{*}{ education } & no school qualifications & 2 & 0.4 \\
\hline & still in school & 4 & 0.8 \\
\hline & junior high diploma & 88 & 17.6 \\
\hline & high school diploma & 193 & 38.6 \\
\hline & university-entrance diploma & 105 & 21.0 \\
\hline & bachelor or master degree & 89 & 17.8 \\
\hline & other degree & 19 & 3.8 \\
\hline net & no income & 26 & 5.2 \\
\hline \multirow[t]{9}{*}{ income } & less than $500 €$ & 30 & 6.0 \\
\hline & $500 €$ up to $1.000 €$ & 46 & 9.2 \\
\hline & $1.000 €$ up to $1.500 €$ & 95 & 19.0 \\
\hline & $1.500 €$ up to $2.000 €$ & 92 & 18.4 \\
\hline & $2.000 €$ up to $2.500 €$ & 69 & 13.8 \\
\hline & $2.500 €$ up to $3.000 €$ & 57 & 11.4 \\
\hline & $3.000 €$ up to $3.500 €$ & 27 & 5.4 \\
\hline & $3.500 €$ up to $4.000 €$ & 25 & 5.0 \\
\hline & $4.000 €$ or more & 33 & 6.6 \\
\hline household & 1 & 121 & 24.2 \\
\hline \multirow[t]{6}{*}{ size } & 2 & 207 & 41.4 \\
\hline & 3 & 92 & 18.4 \\
\hline & 4 & 55 & 11.0 \\
\hline & 5 & 20 & 4.0 \\
\hline & 6 & 4 & 0.8 \\
\hline & $>6$ & 1 & 0.2 \\
\hline
\end{tabular}

Table 1: Sample 


\section{Results}

\subsection{General buying behaviour}

At the beginning of the questionnaire the participants had to indicate where they buy most of their meat products. The classical retailer took the first position $(48.6 \%)$ followed by discount shops $(38.6 \%)$. Butcheries were on third position (10.2\%). All other options were only of minor importance (see Figure 1)

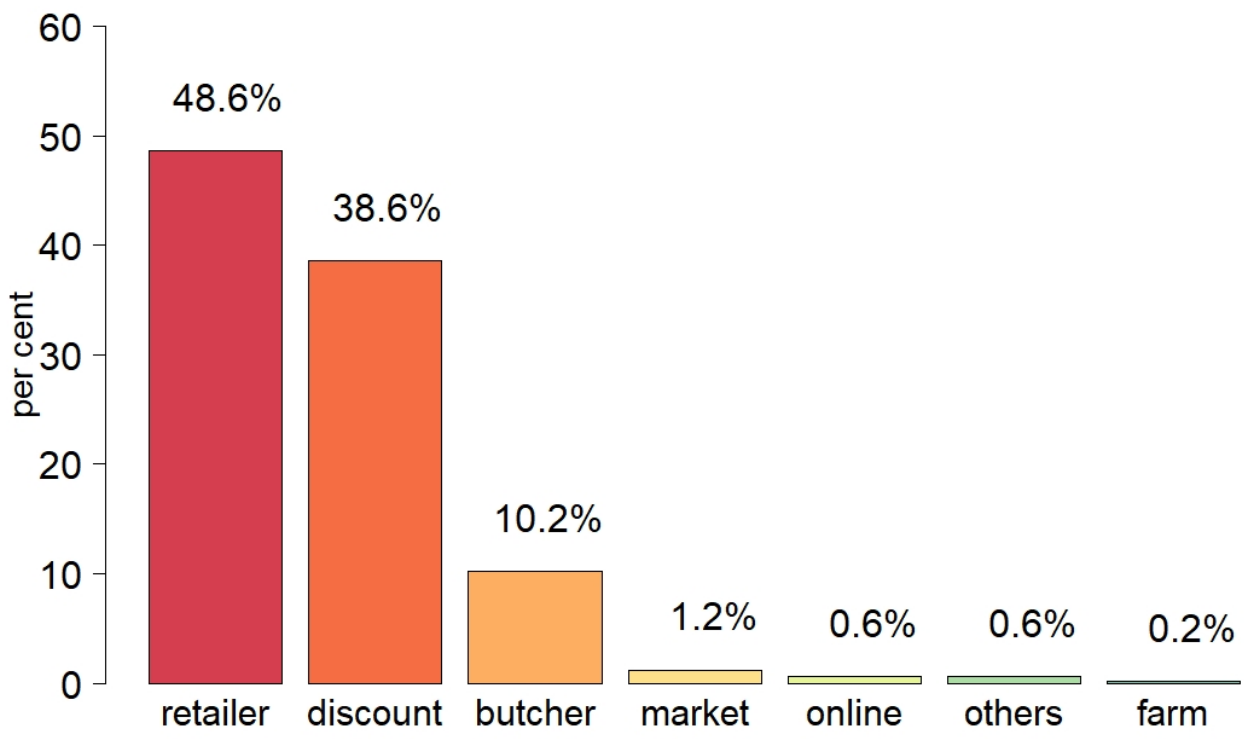

Figure 1: Preferred buying location of meat/meat products

Furthermore, respondents were asked for their buying frequency of organic respectively meat from free-range production. About $22 \%$ of the participants indicated to buy such products often $(18.2 \%)$ or always $(4.2 \%)$ (see Table 2). In 2019 a survey was conducted by Kitchen Stories (Statista, 2019) investigating the purchasing behavior towards organic food in Germany. In the mentioned study, somewhat higher values were found with $13.2 \%$ bought mostly organic products, while for $18.6 \%$ of the respondents organic food made up more than half of the shopping cart.

\begin{tabular}{lr}
\hline & $\boldsymbol{\%}$ \\
\hline never & 15.4 \\
sometimes & 62.2 \\
often & 18.2 \\
always & 4.2 \\
\hline
\end{tabular}

Table 2: Buying frequency organic/free-range meat 


\subsection{Meat Attachement Questionnaire (MAQ) and Food Neophobia Scale(FNS)}

Due to the confirmatory factor analysis the item "I would feel fine with a meatless diet" was deleted from the scale because in the four-factor solution this item has a similar loading on different factors and its deletion increased the calculated indices. The reliability analysis for the global MAQ showed in Germany a high internal consistency with a standardized Cronbach $\alpha$ of 0.86. The Comparative Fit Index (CFI=0.962), the Tucker-Lewis Index (TLI=0.952) and the Root Mean Square Error of Approximation (RMSEA = 0.060) showed acceptable values. In comparison to (Graça et al. 2015) we received higher values for the non-reversed items and lower values for the reversed item what might be due to the fact that vegans and vegetarians were not part of this study (see Table 3). On average respondents agree to all of the statements. The highest means received the statements "I love meals with meat" (3.94) and the reverse-coded item "Meat reminds me of diseases". This evaluation demonstrates that most of the respondents consider meat not as an unhealthy product but as an essential part of their diet. For use in the regression analysis the individual scores, that is the $\mathrm{z}$-standardised mean value across the 14 items were calculated. The higher the MAQ-score is, the higher is indiviudals' attachement to meat. After deleting two items from the original FNS-list due to low item-correlations in the reliability analysis and one item due to the confirmatory factor analysis, FNS showed an acceptable internal consistency with a standardized Cronbach $\alpha$ of 0.76 . The confirmatory factor analysis (two-factor-solution) produced acceptable values for the three considered indices (CFI $=0.961$ TLI=0.937 and RMSEA=0.074). The deleted items were: "I do not trust new (different or innovative) food", "If I don't know what a food is, I won't try it", "I am very particular about the food I eat".

For use in the regression analysis the individual scores, that is the z-standardised mean value across the seven items were calculated. The higher the FNS-score is, the higher is indiviudals' food neophobia.

\subsection{Consumption of substitutes}

The survey questionnaire comprehended several direct questions about the consumption of meat substitutes. In this context respondents were asked if they deliberately substitute meat on the days they do not eat meat. In this context a high proportion of $54.2 \%$ of the respondents stated to choose consciously meatless alternatives (see Table 5.

Subsequently, this group had to indicate with which products they concretely substitute meat. For this purpose they received a list of twelve products from that up to three products could be chosen. The option fish was selected by $48.3 \%$ of this segment, followed by cheese $(47.6 \%)$, eggs $(41.7 \%)$, pasta $(39.5 \%)$ and salad $(35.4 \%)$ as most preferred substitutes (see Table 6). It is to highlight that the top three on the list are non-vegan alternatives whereas vegan alternatives like protein-rich lentils, tofu, or seitan were only of minor importance.

Additionally, all respondents were asked how often they buy plant-based meat substitutes, such as veggie burgers. Interestingly, only $4.0 \%$ indicated to consume such products frequently whereas $14.4 \%$ stated to do so at least sometimes (see Table 7).

\subsection{Comparison meat vs. meathybrid}

In order to analyse the preference for meathybrids in more detail respondents received a comparison task. The question for this task was: "Consider a food product made of $100 \%$ meat and a comparable food product made of $60 \%$ meat and $40 \%$ plant-based proteins. Which product do you think is ... 


\begin{tabular}{llll}
\hline statement & std. $\alpha$ & $\bar{x}$ & $\sigma$ \\
\hline I love meals with meat. & 0.84 & 3.94 & 1.00 \\
To eat meat is one of the good pleasures in life. & 0.85 & 3.38 & 1.08 \\
I'm a big fan of meat. & 0.84 & 3.58 & 1.07 \\
A good steak is without comparison. & 0.84 & 3.76 & 1.12 \\
By eating meat I'm reminded of the death and suffering of animals. (r) & 0.86 & 3.50 & 1.19 \\
To eat meat is disrespectful towards life and the environment. (r) & 0.86 & 3.30 & 1.19 \\
Meat reminds me of diseases. (r) & 0.86 & 3.86 & 1.18 \\
To eat meat is an unquestionable right of every person. & 0.86 & 3.57 & 1.12 \\
According to our position in the food chain, we have the right to eat meat. & 0.86 & 3.68 & 1.13 \\
Eating meat is a natural and indisputable practice. & 0.85 & 3.75 & 0.98 \\
I don't picture myself without eating meat regularly. & 0.85 & 3.56 & 1.14 \\
If I couldn't eat meat I would feel weak. & 0.85 & 3.12 & 1.19 \\
I would feel fine with a meatless diet. (r) & & 3.32 & 1.14 \\
If I was forced to stop eating meat, I would feel sad. & 0.85 & 3.38 & 1.15 \\
Meat is irreplaceable in my diet. & 0.84 & 3.43 & 1.11 \\
\hline
\end{tabular}

Note: 5 -point Likert scale: $1=$ strongly disagree, $2=$ disagree, $3=$ neither disagree nor agree, $4=$ agree, $5=$ strongly agree)

Table 3: Meat attachment questionnaire scale (MAQ)

- healthier?

- tastier?

- more expensive ?

- better for the environment?

- better for animal welfare?

Subsequently, respondents had to indicate if they would pay more either for a meathybrid or meat respectively if they would choose either a meathybrid or a meat product. Concerning the parameters health, environment and animal welfare the meathybrid was evaluated much better then the meat option (see Table 8). Contrarily, meat was perceived as tastier in comparison to the meathybrid by $62.4 \%$ of the respondents. Concerning the willingness-to-pay more for a product only $20.4 \%$ of the interviewees named the meathybrid option and likewise only $27.4 \%$ indicated to choose the meathybrid in the direct comparison.

\subsection{Multinomial logit regression analysis}

In the multinomial regression analysis, it was explored whether the MAQ and the FNS have an impact on the choice decision in the questionnaire. In the mentioned choice task the respondents were directly asked if they would either choose the meat or the hybrid product or none of these products (see section before). Furthermore, the results respectively parameters from the direct comparison (health, taste, environment, animal welfare) between meat and hybrid entered the regression as independent variables as well as the buying frequency of organic/free range meat and the buying frequency of plant-based alternatives (like veggie burger). 


\begin{tabular}{llll}
\hline statement & std. $\alpha$ & $\bar{x}$ & $\sigma$ \\
\hline I am constantly sampling new and different food. (r) & 0.74 & 2.75 & 1.17 \\
I do not trust new (different or innovative) food. & & 2.93 & 1.11 \\
If I don't know what a food is, I won't try it. & & 3.85 & 1.00 \\
I prefer food from different cultures. (r) & 0.72 & 2.59 & 1.07 \\
I am reluctant to eat foreign food that I see for the first time. & 0.74 & 2.96 & 1.21 \\
If I go to a buffet, meetings or parties, I'll eat new food. (r) & 0.73 & 2.32 & 1.09 \\
I'm afraid to eat food that I did not eat before. & 0.73 & 2.49 & 1.23 \\
I am very particular about the food I eat. & & 3.06 & 1.13 \\
I will eat almost anything. (r) & 0.76 & 2.32 & 1.10 \\
I like to try new ethnic restaurants. (r) & 0.70 & 2.36 & 1.10 \\
\hline
\end{tabular}

Note: 5-point Likert scale: $1=$ totally disagree, $2=$ disagree, $3=$ neither disagree nor agree, $4=$ agree,

$$
5=\text { totally agree) }
$$

Table 4: Food neophobia scale (FNS)

\begin{tabular}{lr}
\hline yes & no \\
\hline $54.2 \%$ & $45.8 \%$ \\
\hline
\end{tabular}

Table 5: deliberately substitute meat on the days they do not eat meat

\begin{tabular}{ll}
\hline nr product & \% \\
\hline 1 Fish & 48.3 \\
2 Cheese & 47.6 \\
3 Egg(s) & 41.7 \\
4 Pasta & 39.5 \\
5 Salad & 35.4 \\
6 Other legumes 15.1 \\
7 Lentils & 9.6 \\
8 Nuts & 8.9 \\
9 Tofu & 6.3 \\
10 Seitan & 1.8 \\
11 Other & 1.1 \\
12 Tempeh & 0.4 \\
\hline
\end{tabular}

Table 6: Ranking list consumed meat alternatives 


\begin{tabular}{lr}
\hline & \% \\
\hline never & 45.6 \\
tried it once & 16.0 \\
rarely & 20.0 \\
sometimes & 14.4 \\
frequently & 4.0 \\
\hline
\end{tabular}

Table 7: Frequency of consumption of meat alternatives such as veggie burgers

\begin{tabular}{llll}
\hline & meat & neither/nor & hybrid \\
\hline healthier & $31.0 \%$ & $27.2 \%$ & $\mathbf{4 1 . 8 \%}$ \\
tastier & $\mathbf{6 2 . 4 \%}$ & $20.8 \%$ & $16.8 \%$ \\
more expensive & $26.6 \%$ & $25.8 \%$ & $\mathbf{4 7 . 6 \%}$ \\
better for environment & $15.8 \%$ & $31.0 \%$ & $\mathbf{5 3 . 2 \%}$ \\
better for animal welfare & $15.6 \%$ & $26.8 \%$ & $\mathbf{5 7 . 6 \%}$ \\
I would pay more for ... & $33.0 \%$ & $\mathbf{4 6 . 6 \%}$ & $20.4 \%$ \\
I would choose ... & $\mathbf{5 9 . 4 \%}$ & $13.2 \%$ & $\mathbf{2 7 . 4 \%}$ \\
\hline
\end{tabular}

Table 8: Comparison meat vs. hybrid

The parameters from the direct comparison were re-coded so that +1 reflects the choice of the hybrid (e.g. as more healthy, better for the environment, ...), -1 the choice of meat and zero the choice of the option "neither/nor" (see section before). As reference category for the multinomial logit model the meat option was chosen.

The regression model was checked for indications of multicollinearity by examining the condition index. Values greater than 30 are typically considered as problematic (Cohen, 2013). No violations of limits were found.

It is to highlight that the constant for the meatyhbrid revealed a negative and significant value $\left(-1.470^{* * *}\right)$. This is, the analysed sample has a much higher preference for the reference category meat in comparison to the meathybrid alternative. The MAQ-results demonstrate that the more meat attached the interviewees are, the higher is the probability not to choose the hybrid option $\left(-0.837^{* * *}\right)$ (see Table 9). Furthermore, the extent of food neophobia $\left(-0.254^{*}\right)$ exerted an significant negative effect on this alternative whereas for the buying frequency of organic respectively meat from free range production no significant effect can be measured (0.038).

If respondents evaluated the hybrid as healthier, better for the environment or better for animal welfare in the comparison task the choice probability for this option increased significantly. In this context it is to highlight that the health perception had by far the strongest impact $\left(1.386^{* * *}\right)$ whereas the effect for the environmental and animal welfare perceptions were roughly only half of this size. With increasing buying frequency of plant-based meat alternatives like e.g. veggie burgers likewise the choice probability of the hybrid option increased $\left(0.292^{* *}\right)$.

Interestingly, the taste evaluation in the comparison task had across all independent variables a relatively strong effect on the choice of the hybrid option. That is, if the respondents perceived the taste of the meathybrid as better the choice probability increases substantially.

In Figure 2 the odds ratios for the meathybrid coefficients from the multinomial logit regression are displayed. The fact that the alternative was a hybrid reduces the choice probability by $77 \%$ (odds ratio=0.23). Similarly holds for the situation where the MAQ increases. Due to the fact 
298 that the MAQ is z-transformed an increase about one standard deviation leads to a reduction in

299 the choice probability of $57 \%$.

300 On the other hand the choice probability increases by the factor 4 (odds ratio=4.00) if the con301 sumer perceives the meathybrid as healthier. Therefore, the health perception nearly compensates 302 the existing difference in preference of the alternatives. Likewise, a better assumed/expected taste 303 of the meathybrid substantially increases the preference for this alternative by the factor 3.62. In 304 the situation the hybrid is perceived as better for the environment the choice probability doubles. 


\begin{tabular}{|c|c|c|}
\hline & \multicolumn{2}{|c|}{ Dependent variable: } \\
\hline & $\begin{array}{l}\text { hybrid } \\
\text { (1) }\end{array}$ & $\begin{array}{c}\text { neiter/nor } \\
\text { (2) }\end{array}$ \\
\hline buy. freq. organic/free range & $\begin{array}{l}-0.038 \\
(0.141)\end{array}$ & $\begin{array}{c}-0.328^{* *} \\
(0.166)\end{array}$ \\
\hline healthier & $\begin{array}{c}1.386^{* * *} \\
(0.213)\end{array}$ & $\begin{array}{l}0.533^{* *} \\
(0.210)\end{array}$ \\
\hline more tasty & $\begin{array}{c}1.289^{* * *} \\
(0.205)\end{array}$ & $\begin{array}{c}1.211^{* * *} \\
(0.201)\end{array}$ \\
\hline better for environment & $\begin{array}{c}0.700^{* * *} \\
(0.223)\end{array}$ & $\begin{array}{c}0.102 \\
(0.225)\end{array}$ \\
\hline better for animal welfare & $\begin{array}{l}0.498^{* *} \\
(0.250)\end{array}$ & $\begin{array}{c}-0.430^{*} \\
(0.224)\end{array}$ \\
\hline Food Neophobia Scale (FNS) & $\begin{array}{l}-0.254^{*} \\
(0.149)\end{array}$ & $\begin{array}{l}-0.169 \\
(0.169)\end{array}$ \\
\hline Meat Attachement (MAQ) & $\begin{array}{c}-0.837^{* * *} \\
(0.168)\end{array}$ & $\begin{array}{l}-0.241 \\
(0.171)\end{array}$ \\
\hline buy. freq. plant-based alt. & $\begin{array}{l}0.292^{* *} \\
(0.142)\end{array}$ & $\begin{array}{l}-0.062 \\
(0.170)\end{array}$ \\
\hline Constant & $\begin{array}{c}-1.470^{* * *} \\
(0.234)\end{array}$ & $\begin{array}{c}-0.950^{* * *} \\
(0.171)\end{array}$ \\
\hline Akaike Inf. Crit. & 710.008 & 710.008 \\
\hline
\end{tabular}

Table 9: Multinomial logit regression - results

\section{Discussion}

The results show that more than fifty percent of consumers substitute meat at least occasionally. Thus, about half of the respondents reveal an eligible consumption behavior in respect to sustainability and healthiness at least sometimes. Furthermore, about $18 \%$ indicated to consume sometimes respectively frequently meat alternatives such as veggie burgers. In the carried out direct comparison between meat and meathybrids about $27 \%$ of the respondents choose the latter 


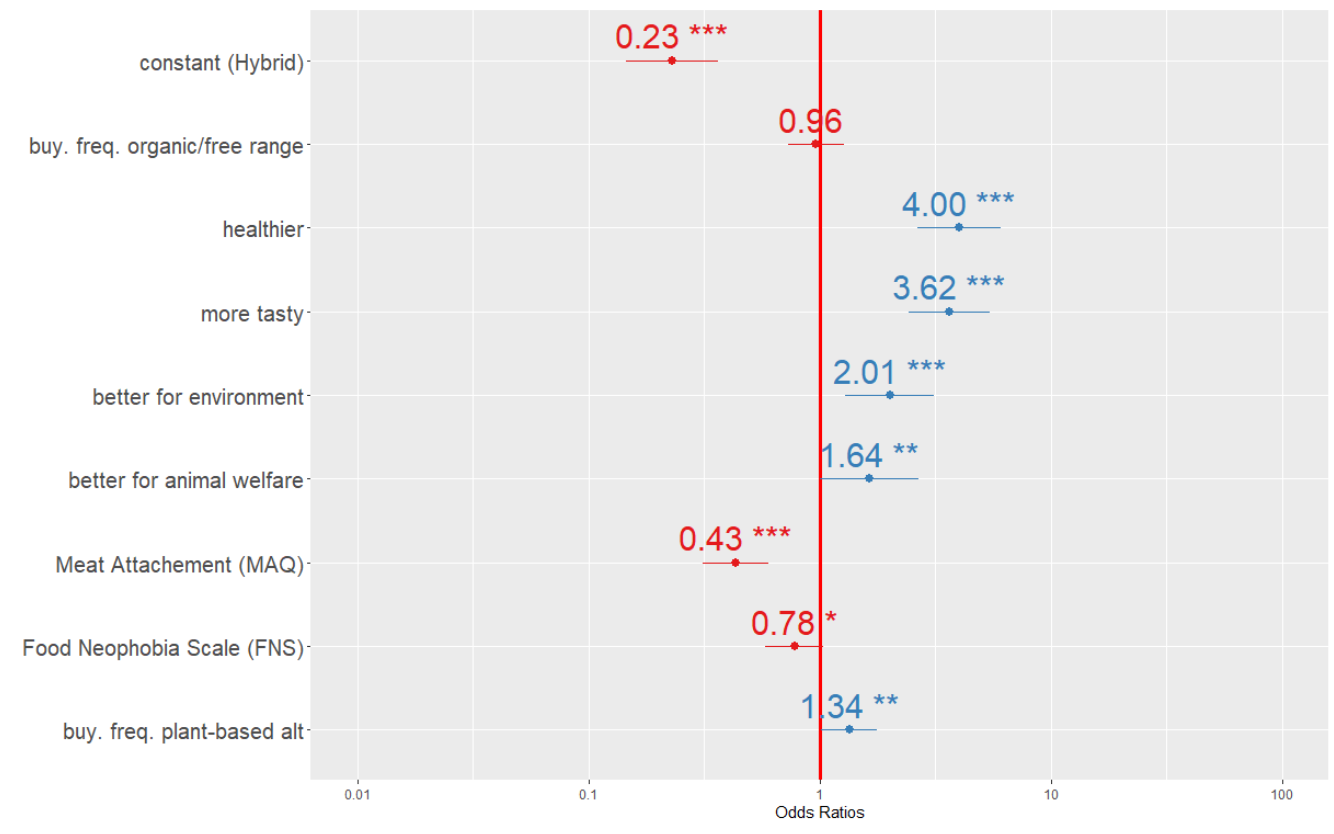

Figure 2: Odds ratios - estimation results meathybrid

alternative. These findings demonstrate that a substantial amount of consumers is open-minded to the "meathybrid" concept. Even a higher share believes that this alternative is healthier, better for the environment and animal welfare in comparison to meat whereas it is perceived as more expensive at the same time.

Concerning the impact factors on choosing either a meathybrid or meat it becomes obvious that the perception of meathybrids as more environment-friendly as well as a more animal-welfarefriendly products positively influence the choice decision. Nonetheless, the by far highest effect is exerted by the health perception. The healthier meathybrids are perceived the higher is the choice probability. Thus this egoistic motive seems to outperform altruistic motives when it comes to choice. In this line, it is to recommend to lay an emphasis on healthy characteristics of meathybrids in product marketing for a successful market entry. These can be used as unique selling proposition (USP) against competitors.

With regard to consumer segments, it can be stated that there is no advantage in focusing on organic buyers as a target group. Across all respondents the parameter buying frequency of organic or meat from free range production had no impact on the choice of a meathybrid product.

Concerning the analysed scales, it can be stated that there is a problem with food neophobia when it comes to meathybrids. The individual degree of food neophobia exerts a negative effect on the choice of this product category. Thus, it can be hypothesized that meathybrids are perceived to a certain degree as 'exotic', 'neo' or 'artificial' as for example burgers based on insects or cultured meat where FNS is likewise a big barrier.

The findings for the MAQ-scale show that the more consumers are attached to meat the lower is the choice probability for choosing meathybrids. Thus for the segment of highly meat attached consumer this alternative is no option. 
Nonetheless, the scepticism of consumers of mixing meat and plant protein has been greatly reduced in recent years. The feeling that the food industry is just willing to increase their turnover by using cheap plant protein in the meat formulation has obviously disappeared. It is to highlight that meathybrids are even perceived as healthier in comparison to meat.

Thus, consumers are nowadays accustomed to found e.g. peas no longer in their original form in foods but also as protein powder. Therefore, the development of hybrid products, which could serve the consumer with the best of both, animal and plant source, will enable all different kinds of consumer groups. This will support all the industrial fields named to get valorisation of highquality new hybrid products.

Especially high-moisture extrusion technology has advanced the production of vegen meat alternatives with high sensory acceptance in the last decade (Asgar et al., 2010, Osen et al. 2014).

\section{Appendix A. Funding notice}

This IGF Project of the FEI is/was supported via AiF within the programme for promoting the Industrial Collective Research (IGF) of the German Ministry of Economic Affairs and Energy (BMWi), based on a resolution of the German Parliament." Project AiF 196 EN

\section{References}

Akwetey, W.Y., Ellis, W.O., Oduro, I.N., 2012. Using whole cowpea flour (WCPF) in frankfurtertype sausages. J Anim Prod Adv 2, 450-455. URL: http://grjournals.com/portals/ grjournals/JAPA/Vol2Issue10/JAPA-2012-10-036-450-455.pdf \{\%\}5Cnfiles/1055/Akweteyetal. -2012-Usingwholecowpeaflour(WCPF) infrankfurter-typ.pdf

Apostolidis, C., McLeay, F., 2016. Should we stop meating like this? Reducing meat consumption through substitution. Food Policy 65, 74-89. URL: http://dx.doi.org/10.1016/j.foodpol.2016.11.002 doi 10.1016/j. foodpol.2016.11.002

Asgar, M.A., Fazilah, A., Huda, N., Bhat, R., Karim, A.A., 2010. Nonmeat protein alternatives as meat extenders and meat analogs. Comprehensive Reviews in Food Science and Food Safety 9, 513-529. URL: https://onlinelibrary.wiley.com/doi/full/10.1111/j.1541-4337.2010.00124.xhttps://

onlinelibrary.wiley.com/doi/abs/10.1111/j.1541-4337.2010.00124.xhttps://onlinelibrary. wiley.com/doi/10.1111/j.1541-4337.2010.00124.x doi 10.1111/j.1541-4337.2010.00124.x

Bernstein, A.M., Sun, Q., Hu, F.B., Stampfer, M.J., Manson, J.E., Willett, W.C., 2010. Major dietary protein sources and risk of coronary heart disease in women. Circulation 122, 876-883. URL: https://pubmed.ncbi.nlm.nih.gov/ 20713902/ doi 10.1161/CIRCULATIONAHA.109.915165

Capiola, A., Raudenbush, B., 2012. The Effects of Food Neophobia and Food Neophilia on Diet and Metabolic Processing. Food and Nutrition Sciences 03, 1397-1403. doi 10.4236/fns.2012.310183

Chalvon-Demersay, T., Azzout-Marniche, D., Arfsten, J., Egli, L., Gaudichon, C., Karagounis, L.G., Tomé, D., 2017. A systematic review of the effects of plant compared with animal protein sources on features of metabolic syndrome1-3.

Journal of Nutrition 147, 281-292. URL: https://pubmed.ncbi.nlm.nih.gov/28122929/ doi 10.3945/jn. 116.239574

Cohen, 2013. Applied Multiple Regression/Correlation Analysis for the Behavioral Sciences. Routledge. doi 10.4324/ 9780203774441

Croissant, Y., 2020. mlogit: Multinomial Logit Models. URL: https://cran.r-project.org/package=mlogit

Damsbo-Svendsen, M., Frøst, M.B., Olsen, A., 2017. A review of instruments developed to measure food neophobia. Appetite 113,358-367. URL:http://dx.doi.org/10.1016/j.appet.2017.02.032 doi 10.1016/j.appet. 2017.02 .032

Dawkins, M., 1980. Animal Suffering. 1 ed., Springer Netherlands. URL: https://www.springer. com/gp/book/9780412225901?utm\{_\}campaign=3\{_\}pier05\{_\}buy\{_\}print $\{\&\}$ utm \{_\}content=

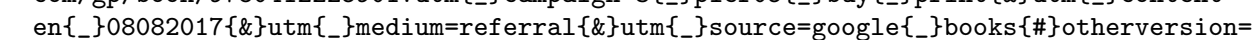
9789400959057 doi 10.1007/978-94-009-5905-7

De Backer, C.J., Hudders, L., 2015. Meat morals: Relationship between meat consumption consumer attitudes towards human and animal welfare and moral behavior. Meat Science 99, 68-74. URL: http://dx.doi.org/10.1016/j. meatsci.2014.08.011 doi 10.1016/j.meatsci.2014.08.011 
De Boer, J., Schösler, H., Aiking, H., 2014. "Meatless days" or "less but better"? Exploring strategies to adapt Western meat consumption to health and sustainability challenges. Appetite 76, 120-128. doi $10.1016 / \mathrm{j}$. appet.2014.02. 002

De Vries, W., Kros, J., Reinds, G.J., Butterbach-Bahl, K., 2011. Quantifying impacts of nitrogen use in European agriculture on global warming potential. doi $10.1016 / \mathrm{j}$. cosust.2011.08.009

Erisman, J.W., Galloway, J., Seitzinger, S., Bleeker, A., Butterbach-Bahl, K., 2011. Reactive nitrogen in the environment and its effect on climate change. doi $10.1016 / j$.cosust. 2011.08 .012

Falciglia, G.A., Couch, S.C., Gribble, L.S., Pabst, S.M., Frank, R., 2000. Food neophobia in childhood affects dietary variety. Journal of the American Dietetic Association 100. doi 10.1016/S0002-8223(00)00412-0

Godfray, H.C.J., Aveyard, P., Garnett, T., Hall, J.W., Key, T.J., Lorimer, J., Pierrehumbert, R.T., Scarborough, P., Springmann, M., Jebb, S.A., 2018. Meat consumption, health, and the environment. Science (New York, N.Y.) 361. doi $10.1126 /$ science. aam5324

Graça, J., Calheiros, M.M., Oliveira, A., 2015. Attached to meat? (Un)Willingness and intentions to adopt a more plant-based diet. Appetite 95, 113-125. URL: https://www.sciencedirect.com/science/article/abs/ pii/S0195666315003189 doi 10.1016/J.APPET.2015.06.024

Grandin, T., 2018. Welfare Problems in Cattle, Pigs, and Sheep that Persist Even Though Scientific Research Clearly Shows How to Prevent Them. Animals 8, 124. URL: http://www.mdpi.com/2076-2615/8/7/124 doi 10 . 3390/ani8070124

Hallström, E., Röös, E., Börjesson, P., 2014. Sustainable meat consumption: A quantitative analysis of nutritional intake, greenhouse gas emissions and land use from a Swedish perspective. Food Policy 47, 81-90. doi 10.1016/j . foodpol.2014.04.002

Hartmann, C., Shi, J., Giusto, A., Siegrist, M., 2015. The psychology of eating insects: A cross-cultural comparison between Germany and China. Food Quality and Preference 44, 148-156. URL: http://dx.doi.org/10.1016/j . foodqual.2015.04.013 doi 10.1016/j.foodqual.2015.04.013

Hartmann, C., Siegrist, M., 2017. Consumer perception and behaviour regarding sustainable protein consumption: A systematic review. Trends in Food Science and Technology 61, 11-25. doi 10.1016/j .tifs.2016.12.006

Henriques, A.S., King, S.C., Meiselman, H.L., 2009. Consumer segmentation based on food neophobia and its application to product development. Food Quality and Preference 20,83-91. doi 10.1016/j.foodqual.2008.01.003

Hu, F.B., 2003. Plant-based foods and prevention of cardiovascular disease: An overview, in: American Journal of Clinical Nutrition, American Society for Nutrition. URL: https://pubmed.ncbi.nlm.nih.gov/12936948/ doi $10.1093 / \mathrm{ajcn} / 78.3 .544 \mathrm{~s}$

Knaapila, A., Tuorila, H., Silventoinen, K., Keskitalo, K., Kallela, M., Wessman, M., Peltonen, L., Cherkas, L.F., Spector, T.D., Perola, M., 2007. Food neophobia shows heritable variation in humans. Physiology and Behavior 91, 573-578. doi $10.1016 / \mathrm{j} \cdot$ physbeh.2007.03.019

Kroeze, C., Bouwman, L., 2011. The role of nitrogen in climate change. doi $10.1016 / \mathrm{j}$.cosust.2011.08.015

Long, J.S., Freese, J., 2001. Regression models for categorical dependent variables using Stata, 2nd Edition. undefined .

Lüdecke, D., 2020. sjPlot: Data Visualization for Statistics in Social Science. URL: https://cran.r-project.org/ package $=$ sjPlot

Macdiarmid, J.I., Douglas, F., Campbell, J., 2016. Eating like there's no tomorrow: Public awareness of the environmental impact of food and reluctance to eat less meat as part of a sustainable diet. Appetite 96, 487-493. URL: http://dx.doi.org/10.1016/j.appet.2015.10.011 doi 10.1016/j.appet.2015.10.011

Max Roser, H.R., Ortiz-Ospina, E., 2013. World Population Growth. Our World in Data .

McAuliffe, G., 2015. A thematic review of life cycle assessment (LCA) applied to pig production. Environmental Im-

1. pact Assessment Review 56, 12-22. URL:https://research-information.bris.ac.uk/en/publications/ a-thematic-review-of-life-cycle-assessment-lca-applied-to-pig-pro

Mullee, A., Vermeire, L., Vanaelst, B., Mullie, P., Deriemaeker, P., Leenaert, T., De Henauw, S., Dunne, A., Gunter, M.J., Clarys, P., Huybrechts, I., 2017. Vegetarianism and meat consumption: A comparison of attitudes and beliefs between vegetarian, semi-vegetarian, and omnivorous subjects in Belgium. Appetite 114, 299-305. URL: http: //dx.doi.org/10.1016/j.appet.2017.03.052 doi 10.1016/j.appet.2017.03.052

Neville, M., Tarrega, A., Hewson, L., Foster, T., 2017. Consumer-orientated development of hybrid beef burger and sausage analogues. Food Science and Nutrition 5, 852-864. doi 10.1002/fsn3.466

Osen, R., Toelstede, S., Wild, F., Eisner, P., Schweiggert-Weisz, U., 2014. High moisture extrusion cooking of pea protein isolates: Raw material characteristics, extruder responses, and texture properties. Journal of Food Engineering 127, 67-74. doi $10.1016 / \mathrm{j} \cdot \mathrm{jf}$ foodeng.2013.11.023

Pliner, P., Hobden, K., 1992. Development of a scale to measure the trait of food neophobia in humans. Appetite 19, 105-120. doi 10.1016/0195-6663(92) 90014-W

Profeta, A., 2019. The Impact of Health Claims in Different Product Categories. Journal of International Food and Agribusiness Marketing doi 10.1080/08974438.2019.1599753

Profeta, A., Hamm, U., 2019. Do consumers care about local feedstuffs in local food? Results from a German consumer 
study. NJAS - Wageningen Journal of Life Sciences 88, 21-30. doi 10.1016/j.njas.2018.12.003

R Core Team, 2020. R: A Language and Environment for Statistical Computing. R Foundation for Statistical Computing. Vienna, Austria. URL: https://www.r-project.org/

Richi, E.B., Baumer, B., Conrad, B., Darioli, R., Schmid, A., Keller, U., 2015. Health risks associated with meat consumption: A review of epidemiological studies. doi 10.1024/0300-9831/a000224

Sans, P., Combris, P., 2015. World meat consumption patterns: An overview of the last fifty years (1961-2011).

Meat Science 109, 106-111. URL: http://dx.doi.org/10.1016/j.meatsci.2015.05.012 doi 10.1016/ j.meatsci.2015.05.012

Siegrist, M., Hartmann, C., 2019. Impact of sustainability perception on consumption of organic meat and meat substitutes. Appetite 132, 196-202. doi 10.1016/j.appet.2018.09.016

Sinha, R., Cross, A.J., Graubard, B.I., Leitzmann, M.F., Schatzkin, A., 2009. Meat intake and mortality: A prospective study of over half a million people. Archives of Internal Medicine 169, 562-571. URL: https://pubmed.ncbi. nlm.nih.gov/19307518/ doi 10.1001/archinternmed.2009.6

Statista, 2019. Germany: organic food purchase 2019. URL: https ://www.statista.com/statistics/1085285/ organic-food-purchase-in-germany/

Stoll-Kleemann, S., Schmidt, U.J., 2017. Reducing meat consumption in developed and transition countries to counter climate change and biodiversity loss: a review of influence factors. Regional Environmental Change 17, 1261-1277. doi $10.1007 / \mathrm{s} 10113-016-1057-5$

Topcu, Y., Uzundumlu, A.S., Baran, D., 2015. How sensory and hedonic quality attributes affect fresh red meat consumption decision of Turkish consumers? Italian Journal of Food Science 27, 53-62. doi 10.14674/1120-1770/ ijfs.v185

Tucker, C.A., 2014. The significance of sensory appeal for reduced meat consumption. Appetite 81, 168-179. URL: http://dx.doi.org/10.1016/j.appet.2014.06.022 doi 10.1016/j.appet.2014.06.022

Verbeke, W., 2015. Profiling consumers who are ready to adopt insects as a meat substitute in a Western society. Food 1. Quality and Preference 39, 147-155. URL: https://www.sciencedirect.com/science/article/abs/pii/ S0950329314001554 doi 10.1016/J.FOODQUAL.2014.07.008

Vidigal, M.C., Minim, V.P., Simiqueli, A.A., Souza, P.H., Balbino, D.F., Minim, L.A., 2015. Food technology neophobia and consumer attitudes toward foods produced by new and conventional technologies: A case study in Brazil. LWT Food Science and Technology 60, 832-840. doi 10.1016/j.lwt.2014.10.058

Young, V.R., Pellett, P.L., 1994. Plant proteins in relation to human protein and amino acid nutrition, in: American Journal of Clinical Nutrition, American Society for Nutrition. URL:https://pubmed.ncbi.nlm.nih.gov/8172124/ doi $10.1093 / \mathrm{ajcn} / 59.5 .1203 \mathrm{~S}$

Zayas, J., Lin, C., 1989. Effect of the Pretreatment of Corn Germ Protein on the Quality Characteristics of Frankfurters. Journal of Food Science 54, 1452-1456. URL: http://doi .wiley.com/10.1111/j.1365-2621.1989. tb05133.x doi $10.1111 / \mathrm{j} .1365-2621.1989 . \mathrm{tb} 05133 . \mathrm{x}$

Zhu, X., van Ierland, E.C., 2004. Protein Chains and Environmental Pressures: A Comparison of Pork and Novel 1] Protein Foods. Environmental Sciences 1, 254-276. URL: https ://www.tandfonline.com/doi/abs/10.1080/ 15693430412331291652 doi $10.1080 / 15693430412331291652$ 